University of Windsor

Scholarship at UWindsor

May 18th, 9:00 AM - May 21st, 5:00 PM

\title{
Exploiting the room for strategic maneuvering in argumentative discourse: Dealing with audience demand in the European Parliament
}

Frans van Eemeren

ILIAS \& University of Amsterdam

Bart Garrsen

Robert Thomas Craig

Follow this and additional works at: https://scholar.uwindsor.ca/ossaarchive

Part of the Philosophy Commons

van Eemeren, Frans; Garrsen, Bart; and Craig, Robert Thomas, "Exploiting the room for strategic maneuvering in argumentative discourse: Dealing with audience demand in the European Parliament" (2011). OSSA Conference Archive. 41.

https://scholar.uwindsor.ca/ossaarchive/OSSA9/papersandcommentaries/41

This Paper is brought to you for free and open access by the Conferences and Conference Proceedings at Scholarship at UWindsor. It has been accepted for inclusion in OSSA Conference Archive by an authorized conference organizer of Scholarship at UWindsor. For more information, please contact scholarship@uwindsor.ca. 


\title{
Exploiting the room for strategic maneuvering in argumentative discourse: Dealing with audience demand in the European Parliament
}

\author{
FRANS H. VAN EEMEREN
}

ILIAS \& University of Amsterdam

The Netherlands

F.H.vaneemeren@uva.nl

\section{BART GARSSEN}

\author{
ILIAS \& University of Amsterdam \\ The Netherlands \\ b.j.garssen@uva.nl
}

\section{THE CONTEXTUALIZATION OF STRATEGIC MANEUVERING IN COMMUNICATIVE ACTIVITY TYPES}

Against the background of the standard pragma-dialectical theory, some fifteen years ago Van Eemeren and Houtlosser set about to extend the available analytic and evaluative tools by introducing the notion of 'strategic maneuvering' (van Eemeren \& Houtlosser 2002). Strategic maneuvering refers to the arguers' continual efforts to reconcile in their argumentative moves aiming for effectiveness with being reasonable. Strategic maneuvering takes place in all stages of the argumentative process of resolving a difference of opinion on the merits. Taking account of the strategic maneuvering involved in argumentative discourse means integrating rhetorical insights into the pragma-dialectical framework for analysis and evaluation. In Strategic Maneuvering in Argumentative Discourse, a monograph van Eemeren published last year, he has made clear in what ways taking account of the strategic maneuvering leads to deeper and more precise analyses and evaluations, which can — on top of that — be accounted for more thoroughly (van Eemeren 2010).

Strategic maneuvering manifests itself in all argumentative moves in the choice that is made from the 'topical potential' available at a particular point in the discourse, the adaptation to 'audience demand', and the 'presentational devices' that are used. Because these three aspects of strategic maneuvering always manifest themselves simultaneously, they can only be distinguished analytically. However, in order to achieve a satisfactory analysis, all three aspects need to be taken into account, together with their mutual interaction. When strategic maneuvering is also taken into account in the evaluation of argumentative discourse, the evaluation concentrates in the first place on 'derailments' of strategic maneuvering in which one or more of the rules for critical discussion have been violated, so that a fallacy has been committed. Incorporating strategic maneuvering in the analysis and evaluation of argumentative discourse requires in both cases taking account of the 'macro'-context of the kind of communicative practice in which the discourse takes place. This is necessary because the contextualization of the discourse in a specific 
'communicative activity type' may create certain preconditions for strategic maneuvering that must be considered in the analysis and the evaluation. ${ }^{1}$

Strategic maneuvering in argumentative discourse can only be studied in the context of real-life communicative activities. These communicative activities are always in some way connected with certain more or less institutionalized contexts, such as the legal context, the political context or the interpersonal context, in which they serve institutionally relevant purposes. ${ }^{2}$ In the various kinds of contexts, the types of communicative activities pertinent to the context concerned will have become conventionalized in accordance with varying kinds of requirements. As a consequence, in the argumentative discourse taking place in such communicative activity types the possibilities for strategic maneuvering are to some extent determined by certain institutional preconditions. This means that in the analysis and evaluation of argumentative discourse due attention needs to be paid to the macro-context of the communicative activity type in which the discourse takes places and the institutional preconditions this activity type imposes on the strategic maneuvering (van Eemeren \& Houtlosser 2005; van Eemeren 2010: 129-162).

\section{CHARACTERIZING COMMUNICATIVE ACTIVITY TYPES ARGUMENTATIVELY}

Defining a communicative activity type amounts to describing, starting from the communicative domain to which the communicative activity belongs, the institutional conventions of the activity type that are instrumental in realizing the 'institutional point' of the activity type through the use a particular 'genre' of communicative activity. In some strongly formalized communicative activity types the institutional conventions may be fully explicit constitutive or regulative rules. In less formalized communicative activity types the institutional conventions are largely implicit rules of some kind, informally established practices or simply extractions of common usage. ${ }^{3}$ The conventionalization of every communicative practice that can be intersubjectively recognized as a communicative activity type may be deemed dependent on the rationale of the existence of the communicative activity that constitutes its institutional point.

The institutional point of a communicative activity type reflects the institutional needs the communicative practice aims to satisfy. In the communicative domain to which the communicative activity type belongs the institutional point manifests itself in all speech events that are specimens of that communicative activity type. Although individu-

1 The concept of activity type is explained in more detail in van Eemeren (2010: 129-163). Levinson described an activity type as a "fuzzy category whose focal members are goal-defined, socially constituted, bounded, events with constraints on participants, setting, and so on, but above all on the kinds of allowable contributions" (1992: 69).

2 We use the term institutionalized in a very broad sense, so that it refers to any established macrocontext in which certain communicative conventions have developed.

3 This approach connects with "rational choice institutionalism" within New Institutionalism (March \& Olsen 1984: 734). According to Hall and Taylor, rational choice institutionalism draws our attention to "the role that strategic interaction between actors plays in the determination of political outcomes" (1996: 951). 
al speech events can very well be examined for their own sake, ${ }^{4}$ when we examine speech events as argumentation theorists we generally view them as tokens, instantiations or representations of a communicative activity type we are interested in. Our attention is then concentrated on a particular communicative activity type as a communicative practice whose conventionalization serves the institutional needs of a certain domain of communicative activity through the implementation of a specific genre of communicative activity in actual speech events. ${ }^{5}$

Communicative activity types may very well be non-argumentative. More often than not, however, in communicative activity types argumentation plays a part, whether structurally or incidentally. A public debate, for example, is inherently argumentative, and a political interview is argumentative in essence. As a rule, love letters and prayers, for instance, are not argumentative, but even they may coincidentally be argumentative. This is, for example, the case when the writer of the love letter or the one who says the prayer tries to make things go his way by supporting the desired outcome of the speech event with arguments. When communicative activity types that are inherently or essentially argumentative, or other communicative activity types with argumentative components, are analyzed for their argumentative dimension, so that these communicative activity types are characterized argumentatively, it can be said that they are viewed as argumentative activity types (van Eemeren \& Houtlosser 2005).

In characterizing a communicative activity type argumentatively, the pragmadialectical model of a critical discussion can be instrumental. Depending on the requirements of the institutional context concerned, in the various argumentative activity types that can be distinguished in argumentative reality the four stages of a critical discussion will be "realized" in different ways. In their empirical counterparts in the speech events actualizing certain argumentative activity types, the stages of a critical discussion take a specific shape, which differentiates the various activity types in argumentatively relevant ways from each other. In characterizing the activity types argumentatively it must therefore be determined what the distinctive features are of the way in which the four stages of a critical discussion manifest themselves in these activity types in their empirical counterparts. This means that a characterization needs to be given of the way in which the confrontation stage manifests itself in the activity type prototypically in the 'initial situation', the way in which the opening stage manifests itself prototypically in the procedural and material 'starting points', the way in which the argumentation stage manifests itself prototypically in the 'argumentative means and criticism', and the way in which the concluding stage manifests itself prototypically in the kind of outcome of the activity.

4 This happens, for instance, when a case study of a certain historical text is conducted, as van Eemeren and Houtlosser $(1999,2000)$ did with the Apologia pamphlet published by William the Silent in 1580 in response to the Ban Edict issued by King Philip II of Spain.

5 As explained in van Eemeren and Houtlosser (2005), communicative activity types are not on a par with theoretical constructs such as the pragma-dialectical ideal model of a critical discussion. While theoretical constructs are based on analytic considerations concerning the best way of reaching a certain (abstract) objective (such as resolving a difference of opinion on the merits), communicative activity types are empirically-based prototypes of conventionalized communicative practices. By distinguishing ideal models in this way between from argumentative activity types, we deviate from approaches to argumentative discourse types such as Walton and Krabbe's (1995). See van Eemeren, Houtlosser, Ihnen and Lewinski (2010). 


\section{EXTRINSIC CONSTRAINTS ON STRATEGIC MANEUVERING IN POLITICAL DELIBERATION}

In this paper we would like to concentrate on some problems involved in analyzing and evaluating strategic maneuvering by means of deliberation in the political domain. Although we will only discuss strategic maneuvering in the plenary debate in the European Parliament, political deliberation also takes place in other communicative activity types, such as - to mention just a few examples examined by our research group in Amsterdam - the so-called general debate in Dutch Parliament, political interviews, and the 'lawmaking debate' and Prime Minister's Question time (PMQ) in British Parliament. ${ }^{6}$ The general institutional point all these communicative activity types have in common on an abstract level is preserving democracy by deliberation. These communicative activity types differ, however, in their specific institutional aims and conventions. In the case of the general debate in Dutch Parliament, for instance, the specific institutional aim is to confront the government with the views of the elected representatives of the Dutch people on their policy plans and their financial backing. The institutional conventions of the general debate and its format are laid down in parliamentary procedure supplemented by established parliamentary tradition.

Each in their own way, the deliberative communicative activity types in the political domain we are concentrating on involve a discussion of political issues in front of an audience consisting of people who may be actively engaged in the discussion or not. As a rule, the format of the discussion is established in such a way that it imposes certain extrinsic constraints on the strategic maneuvering - extrinsic because they are not inherent in strategic maneuvering. The format may, for instance, determine beforehand who decides about the speaking turns and whether there is a possibility of interruptions. It may even be determined that the participants may only address the chair of the meeting and that this chair judges the relevance of the contributions that are made. In these communicative activity types, in their critical exchanges, the parties always have to act in accordance with the explicit or implicit procedural rules of the communicative activity type concerned.

Among the extrinsic constraints imposed on the strategic maneuvering in the plenary debate in the European Parliament are not only institutionally determined regulations, such as the debate format. There are also extrinsic constraints of a different kind, which are not inherent in the European Parliament as an institution but go nevertheless together with it. The most striking of these constraints is the general precondition that we have dubbed "the European Predicament" (van Eemeren \& Garssen 2009). The term European Predicament refers to the fact that at this point in time the Members of the European Parliament (MEPs) are not in the position to promote only the European cause, as they are officially expected to do, but have to make sure that they also keep in mind the particular interests of the country that elected them and pursue their national cause as well. More strongly than parliamentarians representing a certain local constituency in national parliaments, they are forced to support their national interests emphatically. ${ }^{7}$

6 See Tonnard (2009), Andone (2009), Ihnen (2010), and Mohammed (2009), respectively.

7 As we showed earlier, in particular when agriculture or industry is at issue, MEPs who feel that their country will not really benefit from the legislation that is proposed (or may even suffer from it) are inclined to promote views or propose amendments that better combine serving the interests of the European Union with protecting their national interests (van Eemeren \& Garssen 2010). 
Otherwise they will be severely criticized, not just by their own voters but by their home country in general. It is clear, for example, from the contributions made by certain MEPs to the plenary debate in European Parliament about the growing of tobacco that they are fully aware of their unofficial national obligation. This is why next to 'primary preconditions' for strategic maneuvering, which are as a rule official, usually formal, and often procedural, we distinguish also 'secondary preconditions', which are as a rule unofficial, usually informal, and often substantial (van Eemeren 2010: 152).

Next to the European Predicament, more specific preconditions can be mentioned that play a part in pursuing the institutional point of the activity type of plenary debate in the European Parliament which are secondary preconditions for the strategic maneuvering. Just as in other types of political deliberation, the political goals that are pursued by the participants in the debate are a secondary precondition for the strategic maneuvering. Because the plenary debate is conducted between MEPs belonging to different Political Groups, this precondition constitutes a factor pertinent to the analysis. Another secondary precondition stems from the typical place the European Parliament occupies in the institutional organization of the European Union (EU). The European Parliament has in particular close ties with two other institutional bodies, the Council of the EU, consisting of government ministers from all member states, and the European Commission, the politically independent institution upholding the interests of the EU as a whole. ${ }^{8}$ In accordance with the so-called co-decision procedure, the European Parliament decides together with the European Council on legislation and policies initiated and proposed by the European Commission. The plenary debate can be attended both by members of the Commission and by members of the Council. A normal procedure for MEPs is, for instance, to ask questions in writing questions to European Commissioners. Often these questions are about new regulations or policies proposed by the Commission. Such a written question can give occasion to a debate that is attended by the Commissioner responsible for the regulation at hand. Characteristically, the debate then opens with the 'author' of the question reading it out to the Parliament. Next, the commissioner replies to the question and subsequently MEPs react. This results in a rather complex situation, because the MEPs are addressing several audiences at the same time.

\section{THE COMPLEXITIES OF DEALING WITH AUDIENCE DEMAND IN POLITICAL DELIBERATION}

Adaptation to audience demand in strategic maneuvering has to do with securing communion with the people the argumentative discourse is aimed at. As has been recognized in the pragma-dialectical meta-theoretical principle of socialization, argumentative discourse is always aimed at achieving certain communicative and interactional effects on an audience. In order to be able to achieve these effects, the argumentative moves that are made must at each stage of the resolution process connect well with the audience's frame of reference, so that they will be optimally acceptable. This requirement makes it necessary to go into the question of who the audience consists of and which are their relevant views and preferences.

8 There usually is a real opposition between the European Parliament and the two other European institutions. 
It may be the case that the arguer only wants to reach his immediate addressee(s), but it also happens that, additionally, he intends his argumentation to affect others (or his argumentation may affect others unintentionally ${ }^{9}$ ). These others can be people who are present when the argumentation is delivered but do not participate actively in the discussion, but they can, for instance, also be listeners to a radio broadcast of a speech delivered to another audience or television viewers watching a discussion between politicians. Other examples of intended 'third party' audiences are the readers of a polemic between newspaper columnists and the scholars reading a discussion between some of their colleagues in a scholarly journal. In all these cases, the protagonist of a standpoint addresses in fact more than one antagonist. In such a 'triadic argument' (or even more complex exchange) there is, next to the 'official' antagonist, who is addressed directly by the protagonist, some third party antagonist, addressed indirectly, who also judges the acceptability of the argumentative moves that are made. In certain cases the third party antagonist's verdict may even be the more important one, such as when in an election debate between politicians potential voters are addressed indirectly as a third party antagonist.

When it is clear which audience represents the antagonist the arguer considers the more important one to affect, we call these people the arguer's primary audience. The person or persons directly addressed by the protagonist then represent the arguer's secondary audience. In an election debate conducted on television between two politicians, for instance, it is clear from the outset that there is a dual audience and that the politicians consider the viewers at home their primary audience. Each other they will consider only their secondary audience, even to the extent that they do in fact not really aim to convince each other of their standpoints. The argumentation they advance to each other in the debate will be primarily calculated to convince the viewers - or at least the largest possible part of the viewers susceptible to their views - and the debate with each other is made instrumental in achieving this purpose. However, in order not to be viewed as non-cooperative, unresponsive, impolite or even rude, inadequate or incompetent by their primary audience, each party taking part in the debate must take due note of the other party's statements, critical questions and other argumentative moves, and needs to respond to them in a satisfactory way. Although in this kind of political deliberation the political opponent that is addressed directly is as a rule not the primary target for convincing, the argumentative moves he makes need to be dealt with adequately all the same. A vital part of the strategic maneuvering going on in such political deliberation is aimed at doing exactly that.

As a matter of course, the audience addressed in political deliberation with a third party audience is hardly ever completely homogenous. In a public debate on politics, for instance, a protagonist's official antagonists, who are in this case his secondary audience, have as a rule rather different political views and preferences than the protagonist because they represent other political parties in the debate than the protagonist. The primary audience consists in this case of the people attending the debate who the protagonist regards as his potential voters. If the primary audience is homogenous, it can be regarded as a "collective" antagonist (just as a homogenous group of advocates of a

$9 \quad$ Ede and Lunsford (1984) distinguish between the 'audience addressed', which consists in principle of people who are physically present when a speech is delivered, and the 'audience invoked', which refers to the intended audience. This is not the same distinction as I make here, because people who happen to listen in can be present when the argumentation is delivered without being the intended audience. See also van Eemeren and Grootendorst (2004: 99). 
standpoint can be regarded as a "collective" protagonist). Often, however, the people attending or viewing a political debate will differ not only in the way they speak or dress, but also in ways more relevant to their appreciation of the argumentative moves that are made. They may, for instance, have different professional and cultural interests so that different kinds of issues and considerations are important to them. An audience which is heterogeneous with respect to the points at issue or the starting points of the argumentative exchange is called a composite audience.$^{10}$ In analyzing and evaluating the management of audience demand in strategic maneuvering in the communicative activity types of political deliberation not only the difference between primary and secondary audiences, but also the composition of composite audiences needs to be taken into account.

\section{THE AUDIENCE'S FRAME OF REFERENCE AND THE ARGUMENTATIVE SITUATION}

In a dialectical perspective on argumentative discourse, such as the pragma-dialectical one, the audience is always considered to be an active and critical discussion partner of the protagonist, an antagonist, ${ }^{11}$ even if the discourse takes place in an argumentative activity type that is not dialogical. In the analysis of argumentative discourse taking such a dialectical approach involves reconstructing systematically the commitment sets that have developed for the protagonist and the antagonist at the point in the discourse the analysis focuses on. The results of the reconstruction will be different at every point in the discourse, so that the inherent dynamics of argumentative discourse is reflected in the analysis. In this respect, the pragma-dialectical approach, however different its theoretical orientation may be, is fully in line with Tindale's ambition "to capture and express the dynamics of argumentation as a communicative process" (2004: xi). ${ }^{12}$

In argumentative practice, adaptation to audience demand amounts to choosing the argumentative moves that are made in such a way that there is the broadest possible zone of agreement between the relevant views and preferences of the arguer and the audience. This means that, on the one hand, the arguer adopts, as much as his strategic purposes allow him to do, at every point in the discussion the frame of reference that, going by its avowed commitments, the audience may be expected to have. It means that, on the other hand, the arguer tries to convey, as much as the audience's views and preferences seem to allow him to do, the kind of perspective on the argumentative situation that he intends the audience to have. In choosing his arguments in an audience-directed way he may, for instance, consider that certain arguments among the arguments ready for topical selection create exactly the

10 Others just speak of a heterogeneous audience (e.g. Ede \& Lunsford 1984). Benoit and d'Agostine (1994) use the term multiple audience. Perelman and Olbrechts-Tyteca (1958/1969: 21) use the term composite audience when different groups are simultaneously addressed.

11 than merely persuade, they presume that the audience consists of discussants that are in principle out to establish in a reasonable way whether the standpoints at issue are acceptable. For the distinction between convincing and persuading, see van Eemeren and Grootendorst (1984: 48-49).

12 Although it is often not recognized, according to Tindale, "rhetorical argumentation is dialogical. That is, there is a dynamic sense of dialogue alive in the context" (2004: 89). To pragma-dialecticians such a dialogical rhetoric makes it easier to establish connections with their own (dialogical) theoretical framework than would be the case if rhetoric were monological, as it often appears to be. 
kind of perspective on the argumentative situation that suits his strategic purposes well while it also connects with the audience's avowed views and preferences. ${ }^{13}$

Adaptation to audience demand takes place - in combination with the management of the other aspects of strategic maneuvering - in all discussion stages argumentative discourse has to go through. It may manifest itself in the confrontation stage, for example, in keeping the difference of opinion at issue non-mixed to avoid creating contradictions between the positions of the parties that are hard to solve. Perelman and Olbrechts-Tyteca (1969) have pointed out that one way of avoiding unsolvable contradictions is to communicate a disagreement regarding values as a difference of opinion over facts, because the latter is generally easier to deal with. In the opening stage, adaptation to audience demand may, for instance, consist in giving presence only to starting points that the audience has no problems with and putting the difference of opinion in a perspective that is favorable to its resolution. Adaptation to audience demand in the argumentation stage may involve choosing only those arguments that agree with the interest sphere of the audience. In the concluding stage, finally, it may consist in portraying the result of the discussion in such a way that exasperating the audience by rubbing in consequences that are not to their liking is avoided.

Taking account of the frame of reference of the audience means that the views and preferences of the audience need to be identified which may be considered to belong to their starting point. In this endeavor a distinction can be made between 'descriptive' commitments, which relate to what Perelman and Olbrechts-Tyteca (1969) call 'the real' (and include facts, truths and presumptions), and 'normative' commitments relating to 'the preferable' (which include values, value hierarchies and loci). The normative commitments in particular may vary to some extent between different audiences and different members of the same audience. In adapting in their strategic maneuvering to their (primary and secondary) audience's demand, the discussants will have to rely on their audience's commitments. They have to rely not only on the explicit commitments expressed in the opening stage, which can be viewed as "concessions", but also on the implicit "contextual commitments" pertaining to the argumentative situation and the commitments consisting of generally accepted views and preferences which have been known since Aristotle as endoxa. ${ }^{14}$ Together these commitments define the audience's frame of reference.

Next to the commitments that are part of their frame of reference as an audience the parties taking part in argumentative discourse have also acquired commitments by making the argumentative moves they have made in the discourse. These commitments can be externalized by identifying the (direct or indirect) speech acts the parties have performed in making these moves. They can be derived from the identity and correctness conditions applying to these speech acts. ${ }^{15}$ In this way the analyst can determine the sets of commitments the parties have accumulated at a certain point in the discourse, which define the 'dialectical situation' at that point. Together with the 'rhetorical situation', defined by commitments to be identified with the help of contextual information and the

13 For the kind of "framing" involved in this endeavor, see van Eemeren (2010: 112, 126-127).

14 Endoxa refers to the views generally accepted in a specific culture or subculture. Referring to Aristotle's Topics, Irwin (1988) defines endoxa as commonly held beliefs (p. 8) and "beliefs of the many or the wise or both" (p. 37).

15 For the identity and correctness conditions of speech acts, see van Eemeren and Grootendorst (1992: 30-33). 
institutional conventions of the communicative activity type in which the argumentative discourse takes part, the dialectical situation provides a full picture of the argumentative situation at a particular point in the discourse. ${ }^{16}$ In handling audience demand in their strategic maneuvering, the arguers have to deal both with the requirements stemming from the views and preference that define their audience's frame of reference and with the requirements stemming from the commitment sets of the discussants that define the argumentative situation.

\section{ADAPTING TO AUDIENCE DEMAND IN THE PLENARY DEBATE IN THE EUROPEAN PARLIAMENT}

As an illustration of the complexities involved in strategic maneuvering in political deliberation, we focus in this paper on the intricacies of adapting to audience demand in the plenary debate in the European Parliament. Political deliberation in the argumentative activity type of such a debate starts, as a rule from differences of opinion about policy issues between MEPs or Political Groups and (members of) the European Commission. Usually these differences of opinion take the form of a mixed disagreement. If it concerns a proposal or bill introduced by the European Committee, then there may also be a mixed difference of opinion between certain MEPs or Political Groups. This means that there will in fact be several mixed disagreements about the same issue at the same time.

The primary audience of each MEP consists of the fellow MEPs expected to be open to considering accepting the standpoint defended by that MEP, because it is in the end the European Parliament that will decide. However, the member of the European Commission member who made the proposal and the other MEPs or Political Groups represented in the European Parliament will also be addressed by the MEP. As long as the MEP has the intention to convince them, the Commission member and the MEPs who are not expected to be open to considering accepting the standpoint are not just a secondary audience but part of the primary audience. Because the sessions of the European Parliament are only scarcely watched or reported to the voters, the electorate hardly counts as an audience, not even as an inactive one, and is in practice virtually never the primary audience. A complication connected with the primary audience consisting of fellow MEPs who may be inclined to respond positively is this audience is often heterogeneous, if only because the European Predicament applies and there are even within Political Groups almost always certain political differences. If such differences regarding the issues or the starting points of the discussion exist, the primary audience is also a composite audience. ${ }^{17}$

The following plenary debate on freedom of information, held in the European Parliament on October 8, 2009, provides an example of a difference of opinion between an MEP and the European Commission which involves, since the European Parliament

16 Tindale considers 'the rhetorical audience' to be a "complex and fluid" idea, because "audiences change, even in the course of argumentation" (2004: 21). Granting that during the exchange an audience my subtly change in a psychological sense, we only speak of a change of audience if some or all active members of the audience are no longer committed to the same definition of the difference of opinion or to the starting points previously agreed upon.

17 If the members of an audience have different positions in the difference of opinion, the composite audience is called a multiple audience and if they have different starting point it is called a mixed audience (van Eemeren 2010: 110). In a great many cases a composite audience will be both multiple and mixed. 
still has to be convinced, at the same time a difference of opinion between the MEP and the parliament as a whole. In other words: there are here two primary audiences or a primary audience that consists of two different parts. European Commissioner Viviane Reding started the debate by stating that the EU institutions should not be used to solve problems which under the existing Treaties are to be solved at a national level. The MEP Sophia in't Veld shows herself to be a true European Parliamentarian by reacting as follows against this standpoint:

\begin{abstract}
I have to confess I was rather shocked by the statement of Commissioner Reding because, indeed, the Member States are primarily responsible for ensuring respect for democracy and fundamental rights. But you are wrong if you say that the EU has no role to play here. First of all, there is Article 6 of the Treaty on European Union, which reads: 'The Union is founded on the principles of liberty, democracy, respect for human rights and fundamental freedoms, and the rule of law, principles which are common to the Member States.' And to prove that that was not just a hollow statement, the European Union furnished itself with Article 7 - the legal instrument to enforce Article 6. Secondly, Mrs Reding, when we are negotiating with candidate states, we insist that they apply the highest standards of press freedom, otherwise they cannot join the European Union.
\end{abstract}

The MEPs constituting the primary audience in plenary debates in the European Parliament are the ones who need to be convinced of the acceptability of new legalization or policy proposals. When a European Commisioner is as a 'third' party present at the debate, MEPs frequently seize the occasion to make it seem as if there is a conflict of opinion between the European Parliament as a whole and the European Commission. The strategic advantage of this to the debater is that it may look as if his standpoint has already been accepted by the Parliament. An example of this occurred in a debate that took place on May 5, 2009, when European Commissioner Mariann Fisher Boel had to react to a series of questions from MEPs about the Commission's proposal to allow labeling wines composed of a mixture of white and red wine as rosé wine. This would give the European wine growers a better position on the world market since in the USA and in other parts of the world these kind of mixtures are already sold as rosé wine. The Italian MEP Elisabetta Gardini reacted as follows:

Not long ago, very recently, in my region - I am from the Veneto - an event was held known as Vinitaly, which is one of the most important events in the world of wine and a hugely successful petition was drawn up there in defence of rosé wines. It was signed by great Italian wineries, great wine producers, but signatures also came from other parts of Europe - signatures came from the public in Holland, France, Spain, Belgium, Luxembourg, Slovenia, Poland, Lithuania and Ukraine. Passion for rosé wine, as you can see, is authentic and knows no borders except, so it seems, within the European Commission, even though we may talk about culture, local values and tradition.

By stating that the passion for real rosé wine is internationally recognized and that the European Commission is the only real opponent to the proposal to protect rosé wine, Ms. Gardini gives the impression that there is a mixed debate between the European Parliament and the European Commission, thus making it look as if the Parliament has already agreed about this issue. This, however, is not the case. There is in fact a mixed disagreement between Gardini and the Commissioner, and the other MEPs may not be in agreement with Gardini at all. 
Françoise Grossetête, one of the MEPs who had asked the questions uses the same kind of tactic. She uses the personal pronoun 'we', as if she can refer to the whole parliament, and talks about 'our' wine growers, thus indicating that this is not just her own opinion or that of her Political Group. On top of that, she stresses by the harsh tone of her concluding remarks the opposition between the European Parliament and the European Commission:

Commissioner, earlier you said that you had not received any suggestions and that you were waiting for proposals, and so on. On the contrary, suggestions have been put to you. You met our wine growers. They told you that they did not want this. They told you that they personally did not want to be forced to specify the designation 'traditional rosé wine' in order to distinguish it from the rosé wine which naturally will not state 'blended'. Therefore you cannot say that no one has suggested anything to you. Above all, with regard to rosé Champagne, we are well aware that it is an oenological product which has nothing to do with the blending as proposed here: white wine and red wine. We are asking you to find the courage, Mrs Fischer Boel, not to call blended white and red wine 'rosé wine'. This is what we are asking you. This is our suggestion to you. Do not penalize real wine growers. How do you expect our fellow citizens to understand such a stance on the part of the European Commission? You turn a deaf ear to all our arguments: this is absolutely incomprehensible.

\section{CONCLUSION}

The purpose of this paper was to illustrate that the room for strategic maneuvering in political deliberation in the plenary debate in the European Parliament is neither exclusively determined by the topical potential of reasonable, i.e. analytically relevant, argumentative moves that can, according to the pertinent dialectical profile, in principle be made by the arguer, nor by the verbal repertoire of presentational options that are in principle available to the arguer for carrying out these argumentative moves. We have shown that the room for strategic maneuvering available to the arguer is also determined by the demands of the audience he intends to address. It depends on the choices he is willing to make in adapting to their frame of reference at the point the strategic maneuvering takes place and on the perspective on the argumentative situation he induces the audience to adopt. If in strategic maneuvering a primary and a secondary audience need to be addressed at the same time and the primary audience and the secondary audience are on top of that not homogeneous, then the audience the arguer intends to address is complex in several respects. Due to the primary and secondary institutional preconditions of this communicative activity type, in the strategic maneuvering that takes place in the plenary debate in the European Parliament this is usually the case. When engaging in this communicative activity type, MEPs need to meet audience demand by making both the adaptations that are required because of the views and preferences that determine in a particular case the frame of reference of (the relevant part of) each audience and the adaptations that are required because of the commitment sets defining in a particular case the argumentative situation for (the relevant part of) each audience. 
FRANS H. VAN EEMEREN AND BART GARSSEN

\section{REFERENCES}

Andone, C. (2009a). Accusing someone of an inconsistency as a confrontational way of strategic manoeuvring. In F. H. van Eemeren (Ed.), Examining argumentation in context: Fifteen studies on strategic maneuvering (pp. 153-170). Amsterdam: John Benjamins.

Benoit, W.L., and D'Agostine, J.M. (1994). "The case of the midnight judges" and multiple audience discourse: Chief Justice Marshall and Marbury v. Madison. Southern Communication Journal 59, 89-96.

Ede, L., and Lunsford, A. (1984). Audience addressed/audience invoked: The role of audience in composition theory and pedagogy. College Composition and Communication 35(2), 155-171.

Eemeren, F.H. van (2010). Strategic maneuverting in Argumentative Discourse. Extending the PragmaDialectical Theory of Argumentation. Amsterdam-Philadelphia: John Benjamins.

Eemeren, F.H. van, and Garssen, B. (2010). Constraints on political deliberation: European parliamentary debate as an argumentative activity type. Controversia 7(1), 13-32.

Eemeren, F.H. van, and Grootendorst, R. (1984). Speech acts in argumentative discussions. A theoretical model for the analysis of discussions directed towards solving conflicts of opinion. Berlin: de Gruyter.

Eemeren, F.H. van, and Grootendorst, R. (1992). Argumentation, communication, and fallacies. A pragmadialectical perspective. Hillsdale, NJ: Lawrence Erlbaum.

Eemeren, F.H. van, and Grootendorst, R. (2004). A systematic theory of argumentation: The pragmadialectical approach. Cambridge: Cambridge University Press.

Eemeren, F.H. van, and Houtlosser, P. (1999). William the Silent's argumentative discourse. In Eemeren, F.H. van, Grootendorst, R., Blair, J.A., and Willard, C.A. (eds). Proceedings of the Fourth Conference of the International Society for the Study of Argumentation (pp. 168-171). Amsterdam: Sic Sat.

Eemeren, F.H. van, and Houtlosser, P. (2000). The rhetoric of William the Silent's Apologie. A dialectical perspective. In: Suzuki, T. Yano, Y., and Kato, T. (eds). Proceedings of the First Tokyo Conference on Argumentation (pp. 37-40). Tokyo: Japan Debate Association.

Eemeren, F.H. van, and Houtlosser, P. (2002). Strategic maneuvering in argumentative discourse: Maintaining a delicate balance. In: Eemeren, F.H. van, and Houtlosser, P. (eds). Dialectic and rhetoric: The warp and woof of argumentation analysis (pp. 131-159). Dordrecht: Kluwer Academic.

Eemeren, F.H. van, and Houtlosser, P. (2005). Theoretical construction and argumentative reality: An analytic model of critical discussion and conventionalised types of argumentative activity. In: Hitchcock, D. and, Farr, D. (eds). The Uses of Argument. Proceedings of a Conference at McMaster University, 18-21 May 2005 (pp. 75-84). Hamilton, ON: Ontario Society for the Study of Argumentation.

Eemeren, F.H. van, Houtlosser, P., Ihnen, C., and Lewinski, M. (2010). Contextual considerations in the evaluation of argumentation. London: King's College Publications.

Hall, P.A., and Taylor, R.C.R. (1996). Political science and the three new institutionalisms. Political studies 44, 936-957.

Ihnen, C. (2010). The analysis of pragmatic argumentation in law-making debates: Second reading of the terrorism bill in the British House of Commons. Controversia 7(1), 91-107.

Irwin, T. (1988). Aristotle's first principles. Oxford: Clarendon Press.

Levinson, S.C. (1992). Activity types and language. In: Drew, P., and Heritage, J. (eds). Talk at work: Interaction in institutional settings (pp. 66-100). Cambridge: Cambridge University Press.

March, J.G., and Olsen, J.P. (1984). The new institutionalism: Organizational factors in political life. The American Political Science Review 78(3), 734-749.

Mohammed, D. (2009). Manoeuvring strategically in Prime Minister's Question Time. In: Eemeren, F.H. van (ed.). Examining argumentation in context: Fifteen studies on strategic maneuvering (pp. 171-190). Amsterdam: John Benjamins.

Perelman, C., \& Olbrechts-Tyteca, L. (1969). The new rhetoric. A treatise on argumentation (Trans.). Notre Dame: University of Notre Dame Press. (Original work published in 1958)

Tindale, C. W. (2004). Rhetorical argumentation: Principles of theory and practice. London: Sage.

Tonnard, Y. (2009). Shifting the topic in Dutch Parliament. How presentational choices can be instrumental in strategic manoeuvring. In: Eemeren, F.H. van (ed.). Examining argumentation in context: Fifteen studies on strategic maneuvering (pp. 221-240). Amsterdam: John Benjamins.

Walton, D.N., and Krabbe, E.C.W. (1995). Commitment in dialogue: Basic concepts of interpersonal reasoning. Albany, NY: SUNY Press. 


\section{Commentary on "EXPLOITING THE ROOM FOR STRATEGIC MANEUVERING IN ARGUMENTATIVE DISCOURSE: DEALING WITH AUDIENCE DEMAND IN THE EUROPEAN PARLIAMENT" by Frans van Eemeren and Bart Garssen}

\section{ROBERT T. CRAIG}

Department of Communication

University of Colorado at Boulder

270 UCB, Boulder, CO 80309-0270

USA

Robert.Craig@Colorado.EDU

\section{INTRODUCTION}

Van Eemeren and Garssen extend the pragma-dialectical theory of strategic maneuvering to account for complex forms of audience demand in particular institutional contexts. They illustrate some of their theoretical points with examples taken from a debate in the European Parliament. The analysis reveals an interesting argumentative move specific to this communicative situation, a tactic that exploits certain institutional tensions within a complex, heterogeneous audience to create a misleading impression that the primary audience as a whole already agrees with the protagonist.

As illustrated by this analysis, the concept of strategic maneuvering has been a very useful addition to the analytical apparatus of pragma-dialectics. Strategic maneuvering refers to the use of rhetorical strategies by arguers who attempt to maximize their practical success without violating the norm of reasonableness articulated through an ideal model of critical discussion. Whereas critical discussion is a normative concept, strategic maneuvering is a descriptive concept intended to facilitate more precise analysis and evaluation of argumentation by taking account of pragmatic elements of the specific institutional setting and communicative activity type in which the argumentation occurs. The analysis allows finer lines to be drawn between argumentative moves that are communicatively strategic but not unreasonable versus moves that actually violate the pragma-dialectical rules of critical discussion, thus committing pragma-dialectical fallacies through what are called "derailments" of strategic maneuvering. Although the argumentative tactic illustrated in this paper is described as having created a false impression in the cases examined, the authors do not explicitly argue that the tactic was fallacious or not in those instances.

While more attention to that issue would have been helpful, the gains in empirical sensitivity and analytical insight afforded by this extension of the theory of strategic maneuvering are nevertheless apparent in this paper and prompt me to reflect on further ways in which the theory could be extended. The remainder of this commentary discusses three aspects of strategic maneuvering not mentioned by van Eemeren and Garssen, all of which I argue are conceptually implied by the ideal model of critical discussion and suggest promising directions for pragma-dialectical research. While the first two of these extensions seem quite straightforward, the third poses an interesting problem for the normative evaluation of strategic maneuvering. Specifically, it implies that in some cases the pragma-dialectical analysis and evaluation of strategic maneuvering must step outside of 
its own normative framework to assess the appropriateness of subordinating of pragmadialectical norms of critical discussion to the competing norms of particular institutions or communicative activity types.

\section{STRATEGIC MANEUVERING IN RETRACTING A STANDPOINT}

To date, the analysis of strategic maneuvering has focused primarily on discursive strategies that are used in advancing and defending standpoints, but the ideal model of critical discussion implies that equal attention should be given to the strategic maneuvering that may be involved in accepting the arguments of opponents and retracting standpoints. The reasonable resolution of a difference of opinion can only occur if all parties are willing to yield to the better arguments of others. This requirement is codified in the Closure rule of critical discussion, which states:

A failed defense of a standpoint must result in the protagonist retracting the standpoint, and a successful defense of a standpoint must result in the antagonist retracting his or her doubts. (van Eemeren, Grootendorst, \& Snoeck Henkemans 2002: 183)

The discursive process of retracting standpoints and accepting the arguments of opponents is particularly interesting, not only because of its important role in the ideal model but also because of the distinct pragmatic concerns that seem likely to influence the strategic maneuvering of arguers in this position. Those concerns may include at least the following:

- A dialectical concern to give up neither more nor less of one's standpoint than is warranted by the current state of the argumentation, which in many cases may be rather uncertain.

- A personal concern to minimize the immediate loss of face or the longer term damage to one's reputation that may result from "losing" an important argument.

- A social concern to minimize the extent to which the retraction of a standpoint may be seen as violating the arguer's commitments to others, for example if the arguer has been speaking on behalf of a group.

Concerns such as these seem likely to produce distinct forms of strategic maneuvering that require empirical investigation. The arguer may retract certain parts or interpretations of her standpoint while attempting to maintain others, or may only admit that she is "possibly" wrong. She may attempt to give the impression that her standpoint has not changed, even while retracting it implicitly in whole or in part (Craig and Sanusi 2000).

Much of this strategic maneuvering seems oriented to minimizing concessions and retaining as much as possible of the arguer's position, but one can imagine situations in which an arguer would choose instead to maximize or even exaggerate her conversion to an opponent's view. This could be done to curry favour with a powerful superior or to display (for example to members of a group on behalf of which the arguer is committed to speak) that the arguer has given up her standpoint, not out of weakness or disloyalty but only because the opponent's case is so terribly overwhelming that it cannot be denied. 


\section{STRATEGIC MANEUVERING TO INFLUENCE HIGHER-ORDER CONDITIONS}

A second aspect of strategic maneuvering that has not received much attention by pragma-dialectical scholars involves maneuvering around the higher-order conditions of critical discussion. As explained by van Eemeren et al. (1993: 31-34) the ideal model of critical discussion constitutes 'a set of 'first-order' conditions for the rational resolution of disagreements" (p. 31), but the possibility for these first-order conditions to obtain depends on at least two levels of higher-order conditions. Second-order conditions involve psychological states of the arguers that make them more or less able or willing to follow the first-order rules of critical discussion. Extreme anger or dogmatism, for example, could cause a failure of second-order conditions. Third-order conditions refer to the social situation in which argumentation occurs, which may facilitate or inhibit arguers from following the rules of critical discussion. Extreme inequalities of power or institutional norms that limit freedom of speech or discourage questioning certain assumptions, for example, could cause a failure of third-order conditions, making critical discussion impossible. Beyond these levels there are fourth-order conditions that affect not only critical discussion but the possibility of communication in general, such as the ability to speak or a physical setting in which the transmission and reception of messages can occur (van Eemeren et al. 1993: 35-36n).

What is particularly interesting for a theory of strategic maneuvering are the ways that arguers may attempt to influence these higher-order conditions in order to make critical discussion more or less possible in a given situation, as well as ways in which arguers may attempt to influence the impressions that audiences have about these higher-order conditions without influencing the conditions directly. Of great normative importance from a pragma-dialectical standpoint are strategic ways that arguers may attempt to influence a situation in order to enhance the conditions for rational deliberation (Jacobs 2000). Beyond such benign strategies lies a largely unexplored field of strategic maneuvering around higher-order conditions through which arguers may attempt to maximize their success while either staying within the bounds of reasonableness or failing to do so, which constitutes a derailment of higher-order strategic maneuvering. For example, an arguer might try to create the impression that an opponent is being unreasonable due to anger or dogmatism, or might subtly suggest that the expression of a certain view is inappropriate or might have negative consequences. Normative assessment of such discursive moves presumably depends on the critic's assessment of the actual state of the higher-order conditions for critical discussion in a given situation. If critical discussion is actually impossible, an arguer can hardly be blamed for pointing to that reality as a reason not to engage. An arguer who strategically maneuvers to enhance the higher-order conditions for critical discussion may be a kind of pragma-dialectical hero, while an arguer who maneuvers to destroy or minimize those higher-order conditions in order to gain strategic advantage (for example, by intimidating an opponent) may be judged harshly. There is, however, another more complicated kind of case that is discussed in the following section. 


\section{STRATEGIC MANEUVERING TO INFLUENCE THIRD-ORDER CONDITIONS: THE PROBLEM OF NORMATIVE EVALUATION}

Is critical discussion always the most reasonable communicative ideal to pursue when a difference of opinion arises? Yes, presumably, under ideal conditions, but perhaps not when the necessary higher-order conditions are insufficiently present. When higher-order conditions fail, we might say that critical discussion should not be pursued only because it is impossible under the circumstances, even though it is normatively the best way of dealing with a difference of opinion - that is, by attempting to achieve a reasonable resolution of the difference. Whether higher-order conditions are satisfied, hence whether critical discussion is possible, is essentially an empirical question answerable by a descriptive analysis. But would we-or, more to the point, a pragma-dialectical critic-ever judge that critical discussion is a normatively inappropriate way to proceed when faced with a difference of opinion? This judgment, I argue, not only depends on the existence of a contrary norm associated with a particular institution or communicative activity type, but also depends on a critical judgment that the contrary norm is rationally warranted and rightly subordinates the pragma-dialectical norm in that context.

To use what is probably a familiar example to most readers of this commentary, consider a teacher who encounters a difference of opinion with a student. Should the teacher engage the student in a critical discussion to resolve the difference of opinion? Maybe, or maybe not. Let us stipulate that the power difference between teacher and student does not pose a higher-order barrier to critical discussion in this case. The teacher, we assume, is an eminently reasonable person who would gladly be proven wrong by the better argument. No, the problem may be that the teacher feels that engaging the student on this particular difference of opinion would be pedagogically inappropriate. Good pedagogy dictates that the teacher should strategically steer the discussion away from that particular disagreement in order to pursue a line of discussion more productive for the student's learning. Has the teacher committed a higher-order pragma-dialectical fallacy by strategically avoiding a critical discussion? Should pedagogical norms subordinate pragma-dialectical norms in this context? This question cannot be answered without defending a normative judgment about the teacher's pedagogy.

The point generalizes to any communicative context in which legitimate reasons for avoiding critical discussion may exist. In such cases the question of higher-order conditions does not refer to the possibility of critical discussion but rather to the normative appropriateness of critical discussion in that context. And this question cannot be answered without stepping outside of the pragma-dialectical model to assess the relative importance of pragma-dialectical norms versus the possibly competing norms of a particular institution or communicative activity type.

This argument has several implications for pragma-dialectics as a field of study. First, it is quite likely that pragma-dialectical norms should be subordinated to other communicative norms in some situations. Second, in order to evaluate the higher-order strategic maneuvering of arguers in those situations, it is necessary to step outside of the ideal model of critical discussion to assess the relative importance of the competing norms in the particular situation. Third, a further implication is that the pragmadialectical approach can be usefully informed by a broader inquiry into the normative structure of various communicative activity types that can inform critical judgments of the relative importance of competing norms in particular circumstances. This line of ar- 
gument suggests a convergence of interest between the pragma-dialectical approach to argumentation and a more broadly communication-theoretic, empirically grounded normative approach such as grounded practical theory (Craig and Tracy 1995). By explaining the contextual validity of situated norms such as reasonable hostility (Tracy, this volume), grounded practical theory has the potential to inform judgments about the relative importance of different communicative norms in particular situations.

\section{CONCLUSION}

Van Eemeren and Garssen have demonstrated the usefulness of extending the analysis of strategic maneuvering to include complex considerations involving heterogeneous audiences in particular institutional contexts and communicative activity types. I hope to have shown that three further extensions of the analysis of strategic maneuvering also hold promise for enriching the pragma-dialectical approach to argumentation. These include the analysis of strategic maneuvering in retracting standpoints, influencing higher-order conditions for critical discussion, and subordinating the norms of critical discussion to competing norms of particular institutions and communicative activity types.

\section{REFERENCES}

Craig, R. T., and Sanusi, A.L. (2000). "I'm just saying": Discourse markers of standpoint continuity. Argumentation 14, 425-445.

Craig, R.T., and Tracy, K. (1995). Grounded practical theory: The case of intellectual discussion. Communication Theory 5, 248-272.

Eemeren, F.H. van, Grootendorst, R., Jackson, S., and Jacobs, S. (1993). Reconstructing Argumentative Discourse. Tuscaloosa, AL: University of Alabama Press.

Eemeren, F.H. van, Grootendorst, R., and Snoeck-Henkemans, A.F. (2002). Argumentation: Analysis, Evaluation, Presentation. Mahwah, NJ: Lawrence Erbaum.

Jacobs, S. (2000). Rhetoric and dialectic from the standpoint of normative pragmatics. Argumentation 14, 261-286. 